\title{
The Current Situation and Countermeasures of Gratitude Education among College Students
}

\author{
Ya-nan $\mathrm{YU}^{1}$ \\ School of Marxism \\ Mianyang Teachers' College \\ Mianyang, China \\ 308811127@qq.com
}

\author{
Ya-jun $\mathrm{YU}^{2}$ \\ College of Life Science and Engineering \\ Southwest University of Science and Technology \\ Mianyang, China \\ 939690116@qq.com
}

\begin{abstract}
Due to gratitude-lacking, the morality landslide occurs frequently among college students. Thus, the purpose of this article is to learn current psychological situation of college students about their consciousness of gratitude, and to enhance the pertinence and effectiveness of moral education in colleges. We listed recent reports referring to the phenomenon of gratitude-lacking among college students and conducted researches in several universities and colleges. We investigated and analyzed the course of gratitude education in colleges and summarized its experiences and inadequacies by employing questionnaires and interviews. The result shows that the current situation of gratitude consciousness among college students can be summarized as follows: no gratitude towards parents, no gratitude towards teachers, lack of kindness and gratitude consciousness, and disrespect of life and neglect of social responsibility. There are 3 reasons account for the lack of gratitude education: the misconception of family education, insufficiency of gratitude education in colleges, and the misleading of social value orientation. We also discussed the countermeasures for gratitude education among college students: family should play a positive role; college gratitude education should be improved; and good social environment should be created.
\end{abstract}

Keywords-Gratitude; Education; Situation; Countermeasures

\section{INTRODUCTION}

In Jul. 2015, Wu Xie-yu, a student of Peking University, killed his mother through an extremely thoughtful way, and was still at large. In October 2008, Cheng Chun-ming, an associate professor at China University of Political Science and Law died with serious injury after a heavy attack in his class, and the murderer was a student in this university. The suicide rate of university students keeps rising year by year. If searching the website "www.baidu.com" with the key words of "doctoral suicide", the relevant web pages is close to $3,000,000$. A variety of negative reports related to college students' moral problems, are too numerous to list. It worth to think that, since social progress has brought us with material abundance and spiritual fulfillment, why the morality landslide of college students occurs so much? We believe that such phenomenon is due to the lack of gratitude.

Gratitude is a kind of understanding, emotion and behavior that appears when a person receives the kindness derived from other people, society or nature, and is willing to pay back [1].

This project is sponsored by Mianyang City Federation of Social Science (grant No. MYS2014SZ07).
The thought of gratitude in the West is influenced by Christianity, which mainly emphasizes the salvation of souls and cultivation of good behavior. It advocates people to be grateful for love and pay it back with good behavior, on the basis of universal love and equality [2]. Gratitude occupies an important position in the Chinese traditional culture. For example, "The favor of a drop of water has been rewarded with the gratitude of a fountain of water", "Throw in peach, quoted in pear", "Such kindness of warm sun, can't be repaid by grass", etc. These idioms and proverbs are the concentrated reflection of gratitude ideas.

College students are an important part in society, and they are the most knowledgeable people who will undertake the course of national prosperity and national rejuvenation. The cultivation of gratitude consciousness and behavior is crucial in the development of college students' personality. Therefore, it is of great significance to have scientific and effective gratitude education among college students for both individual students and the society. Gratitude education in colleges is an important link between the Moral Education and the Ideological and Political Education.

Under the background of harmonious society, it is beneficial for us to discuss the reason and solution for the gratitude-lacking among college students. The results can help us understand the problems of gratitude education in colleges more systematically. It urges colleges to carry out gratitude education properly. Also, it provides an important basis for the practice of the Ideological and Political Education. However, in recent years, the phenomenon of gratitude-lacking among college students is torturing us: whether the current Gratitude education in colleges plays its role?

The purpose of this article is to learn current psychological situation of college students about the sense of gratitude, and to provide reference for gratitude education among college students. We collected recent reports related to gratitudelacking among college students from public media, and investigated several universities and colleges in Mianyang, including Mianyang Teachers' College, Southwest University of Science and Technology, Mianyang Vocational Technical College, and Sichuan College of Culture and Arts. We investigated the current situation of gratitude education at colleges, analyzed the reason for the lack of gratitude, and put forward possible countermeasures for the existing problems at last. Our investigation was performed through questionnaire 
and interviews. In sum, 800 paper questionnaires were delivered, and 723 questionnaires, contributed by 373 boys and 307 girls, were returned. Among them, the number of effective questionnaire is 680 , and the effective rate is $85.0 \%$. The number of students majoring in Literature and History is 212, (accounts for 31\%), Science and Technology 353, (52\%), and Arts 115 (17\%).

\section{The CurRent Situation of Gratitude Consciousness AMONG COLLEGE STUDENTS}

\section{A. No Gratitude Towards Parents}

A lot of students take their parents' love and care for granted. Students from rich family usually indulge and try to keep up with the Joneses without thinking the hardship of their parents. For students that come from a normal family, inferiority arise and they blame their parents for not providing a better living standard. According to the survey, 25\% of students almost never expressed wishes on their parents' birthday, and even nearly $40 \%$ of them don't know the exact date of their parents' birthday.

\section{B. No Gratitude Towards Teachers}

Some college students ignore the kind advice from their teachers with hatred, and even threaten their teachers with violence. For example, in July 2013, a teacher from a famous university in Nanjing called the police when threatened by a student for high marks. According to the survey, 23\% of the students think that there is no need to be grateful to their teachers.

\section{Lack of Kindness and Gratitude Consciousness}

Some college students are so snobbish that interest and benefit is the only thing they think when making friends. They are indifferent to those who offer them helps and aloof towards the society. According to a report of Hubei Daily in August 2007, two-thirds of the 22 donated college students in Xiangfan had never contacted their sponsors, which disappointed the sponsors and made the organizers have to cancel the qualification of some students from receiving further donation. Some of our interviewees believed that they deserved to be sponsored because they did well in their exams and they got the donation through their own efforts

\section{Disrespect of Life and Neglect of Social Responsibility}

Suicide occurs frequently in college representing the lack of responsibility. On the one hand, without thinking how to requite their parents, they end their life incautiously and put their elderly parents into endless misery. On the other hand, they wasted years of investment from society in education, health and emotion, and turned down the opportunity to give back to society.

We believe that all the phenomena mentioned above are ascribed to the lack of gratitude education.

\section{THE REASONS FOR THE LACK OF GRATITUDE EDUCATION}

\section{A. The Misconception of Family Education}

Current college students were born after 80s and 90s. Raised up as the only child, they are spoiled by their parents and grandparents and become egocentric. They are not tough enough when confront with frustration and setback. Hoping that their children could have a bright future, parents pay much attention to the scores rather than other valuable qualities, especially gratitude consciousness. In addition, with the increasing divorce rate, more and more students were raised in a single-parent family. It is very often that parents from a single-parent family are inclined to give children more material comforts while neglecting their needs of love and care, which consequently leads to the students' aloofness. It also makes them become selfish and lack of the virtue of gratitude.

\section{B. Insufficiency of Gratitude Education in Colleges}

Some colleges are influenced by the concept that intellectual ability is more important than moral character. They only pay attention to the cultivation of students' professional skills and pursue high employment rate and the enrollment rate into graduate school, while think little about how to help with the construction of students' moral character. Most gratitude education in colleges focuses on theory delivering rather than internalize the meaning of gratitude with the characteristic of our age. The Course of Ideological and Political Theory in college aims to spread Marxism scientific theory, strengthen communist ideal and faith, and help students establish correct outlook of life, of world and of value. Since gratitude education falls under the category of moral education, it is interspersed in this course every now and then.

\section{The Misleading of Social Value Orientation.}

At present, our country is in a period of transformation from traditional society to modern society, the impact of the new system and new trend will cause changes of social economic benefits and moral ideas, and thus will change people's values. The negative effects of social value orientation are reflected as various phenomena, such as arbitrary behaviors, missing moral models, and lacking credibility. A soldier leaving from army "LeiFengBan" was treated as a mental patient, and was sent to psychiatric hospital repeatedly only because he often does good deeds. The scandal of a domestic actor has occupied the headlines of the primary media for a long time even surpassing the Rio Olympics. Such undesirable social phenomena, to some extent, misled the judgment of college students, and in turn result in the weak sense of gratitude. According to the survey, $17 \%$ of students said they only do their own thing and care nothing about the development of the country. $23 \%$ of the students said that they will not stand up in the first place when the country encounters difficulties. 


\section{COUNTERMEASURES FOR GRATITUdE EDUCATION AMONG COLLEGE STUDENTS}

\section{A. Family Should Play a Positive Role}

Set up the correct outlook of family education that put character-building in the most prominent position [3]. Through the ages, the central idea of family education in China can be interpreted as longing to see one's child have a bright future. If children are hoped to grow up as pillar of the society, knowledge and moral character are both prerequisites. A man of virtue will inevitably take this responsibility. Therefore, if parents wish their children a bright future, they have to make sure their children have the moral character that required to be the pillar of the society which in turn will make them benefit from it for lifelong.

Create a harmonious family atmosphere, and establish harmonious parent-child relationship. Parents treating their children as adults may help to build a healthy and loving environment. Since parents and children are independent individuals, parents should fully respect their children's ideas and put themselves in their shoes, thus helping to eliminate communication obstacles and to understand children's thoughts When children have improper thoughts or behavior, parents should choose the right means to intervene in order to rectify and to avoid negative effects.

Parents should always have a grateful heart, keep good communication with the elders at home, express gratitude when receive help from others, take the initiative to help a person in need, in this way, setting an example for children. As the saying goes, "like father, like son". Children's behavior is largely imitated from their parents; therefore, children are subtly influenced by parents' grateful attitude to life, which help them grow up to be grateful persons.

\section{B. To Improve College Gratitude Education}

It is of great need to set up independent course of moral education in colleges, and to cultivate gratitude consciousness and behavior among college students, which is a try to build the foundation for gratitude education system. If we combine the thought of "universal love" in Christianity and "loyalty", "filial piety", and "righteousness" in the Chinese traditional culture, the connotation of gratitude education is enriched and, the theoretical basis of gratitude education is strengthened.

College teachers and students work together to create a harmonious campus environment. School counselors play an important role in the education of college students. Therefore, it is necessary to improve the quality of counselors and ensure full staffing. On the one hand, students' management department can master the ideological trend of students in time; on the other hand, the humanistic care from school can effectively deliver to each student [4]. A platform should be built for the students from poverty-stricken families, to provide them an opportunity to acquire donation. Effective communication and information exchange are good ways to detect ideological problems among students, and can solve many problems for them.
Gratitude education should be introduced to cultural activities in campus. We can improve gratitude consciousness through lectures, BBS and community activities. On the construction of campus culture, the concepts of "feel kindness" and "be grateful" and "give mercy" also can be put on a prominent position, thus, gratitude can be internalized in one's heart and expressed out as one's behavior. Colleges can invite the sponsors and adopters to communicate regularly in order to strengthen the concept of gratitude. College students should always have a thankful heart for those who have helped them. There is an old saying, "Don't miss doing any good thing no matter how insignificant it looks". Colleges should encourage students to care more about the people and things around them, especially those students in need, and provide assistance at their best. This concrete practice of offering hands when others in need is the most direct and effective way for students to obtain moral sublimation. College students can feel satisfaction during the process of helping others.

\section{To Create Good Social Environment}

The improvement of the gratitude consciousness of college students partially depends on the enhancement of gratitude consciousness in the entire society [5]. Therefore, good social environment must be built to promote the development of gratitude education. Different places can carry out a variety of gratitude education according to its local conditions. In addition, public media, such as, television, radio, newspapers, network, should advocate the gratitude consciousness and behavior and set excellent examples of gratitude among college students. In the long run, pressing the evil and supporting the good will become a habit. And every citizen will approve gratitude and practice gratitude consciously. In this way, bad values, such as, ingratitude, money worship and lack of integrity, will be rejected, and the social morality and the people's quality will be improved [6].

\section{SUMMARY}

In recent years, a variety of negative phenomenon related to morality landslide of college students has been reported. We believe that such phenomenon is due to the lack of gratitude. We collected recent reports related to gratitudelacking among college students from public media, and conducted researches in several universities and colleges by questionnaire and interviews.

The result shows that the current situation of gratitude consciousness among college students can be summarized to 4 aspects: no gratitude towards parents, no gratitude towards teachers, lack of kindness and gratitude consciousness, and disrespect of life and neglect of social responsibility. There are at least 3 reasons accounts for the lack of gratitude education: firstly, the misconception of family education; secondly, insufficiency of gratitude education in colleges; last but not the least, the misleading of social value orientation.

We also discussed the countermeasures for gratitude education among college students: family should play a positive role; college gratitude education should be improved; and good social environment should be created. 


\section{REFERENCES}

[1] Shaoxuan, Zheng, "Causes and Countermeasures of gratitude education. ”Western China Quality Education, vol. 2, pp. 149, August 2016 (In Chinese).

[2] Ruiyan, Xv, "Research on the Missing of Gratitude education and Corresponding Solutions for Undergraduates.” Northeast Normal University, pp. 7-9, 2010 (In Chinese).

[3] Guiquan, Zhang, “Consciousness and Education of Gratitude. ”Forum on Contemporary Education, pp. 32-35, January 2006(In Chinese).

[4] Tingting, Liu, "Research on the Gratitude education among the Post-90s University Students.” Bohai University. 2014(In Chinese).

[5] Ruichun, Zhang, "Missing of Gratitude education and Corresponding Solutions for Undergraduates.” Higher Agricultural Education, pp73-75, May 2007(In Chinese).

[6] S. Adam, The Theory of Moral Sentiments. Beijing, The Commercial Press, 2003(In Chinese). 